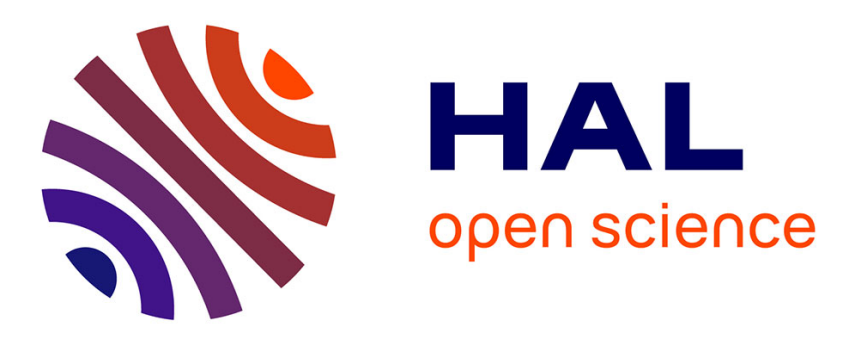

\title{
Mechanical clamp stress on poly(vinyl chloride) infusion tubing: Impact on the surface degradation
}

\author{
Johanna Saunier, Christian Marlière, Alexandre Dazzi, Ariane \\ Deniset-Besseau, Najet Yagoubi
}

\section{- To cite this version:}

Johanna Saunier, Christian Marlière, Alexandre Dazzi, Ariane Deniset-Besseau, Najet Yagoubi. Mechanical clamp stress on poly(vinyl chloride) infusion tubing: Impact on the surface degradation. Journal of Applied Polymer Science, 2020, 137 (43), pp.49324. 10.1002/app.49324 . hal-02346602v2

\section{HAL Id: hal-02346602 \\ https://hal.science/hal-02346602v2}

Submitted on 13 Nov 2020

HAL is a multi-disciplinary open access archive for the deposit and dissemination of scientific research documents, whether they are published or not. The documents may come from teaching and research institutions in France or abroad, or from public or private research centers.
L'archive ouverte pluridisciplinaire HAL, est destinée au dépôt et à la diffusion de documents scientifiques de niveau recherche, publiés ou non, émanant des établissements d'enseignement et de recherche français ou étrangers, des laboratoires publics ou privés. 
1 Mechanical clamp stress on PVC infusion tubing: impact on the surface degradation

2 Johanna Saunier", Christian Marlière ${ }^{2}$, Alexandre Dazzi ${ }^{3}$, Ariane Deniset-Besseau ${ }^{3}$, Najet Yagoubi $^{1}$

51 Université Paris-Saclay Matériaux et santé, 92296, Châtenay-Malabry, France.

$6{ }^{2}$ Université Paris-Saclay, CNRS, Laboratoire de Physique des Solides, 91405, Orsay,

7 France.

$8{ }^{3}$ Université Paris-Saclay, CNRS, Institut de Chimie Physique, UMR 8000, 91405, Orsay,

9 France..

10

11 Corresponding Author: \}.Saunier

12 Email:_iohanna.saunier@universite-paris-saclay.fr:

13

14

15 
Several commercial infusion tubes made of plasticized PVC were shown to present a layer of bloomed species on their internai wall (lubricants and stabilizers), which are poorly soluble in water. During infusion, tubes are crushed and pinched to regulate the flow. The impact of mechanical stress on these layers infusion was studied.

Device inner surfaces were characterized by AFM in order to put into evidence surface degradations before and after infusion. This was correlated with a global and local IR analysis.

24 Because of the clamp stress, the deposits were damaged. Thus, injecting water into the damaged tubing increased the layer degradation. Rolling clamp and pinch clamp may have very different effects on the inner layer morphology and degradation and this may be

27 modulated by the initial layer morphology.

Injecting water into clamp stressed tubing may increase the risk of detaching parts of the internai layer and be a supplementary factor of particulate contamination for the patient.

\section{Keywords}

PVC - Mechanical stress - Surface degradation - Blooming - Particulate contamination Atomic force microscopy

\section{Introduction}

34 Infusion is a very common act in hospitals. Its benefits are widely recognized for the patient in particular in emergency cases, for unconscious patients and for the nutrition of critically ill patients. Infusion is performed by using transparent flexible tubing mostly made in plasticized

$37 \quad$ PVC. This PVC contains several additives such as plasticizers but also stabilizers and

38 lubricants. In a previous paper ${ }^{1}$, we showed that the intemal walls of several PVC infusion

39 tubes were covered by a layer made of additives that bloomed and crystallized onto the PVC 40 surface (metallic stearates and bis amide lubricant). Water contact eroded this layer and we 
suspected it to conduct to a particulate contamination of the infused solution. This particulate contamination is potentially harmful to the patient: depending on the particle's size and shape, on the patient's health and age, it may damage different organs; it may lead to a thrombo-embolization or to the formation of granulomas ${ }^{2} 345$. Moreover, during the infusion, mechanical stress on the tubing can occur because of the use of clamps. Pinch and slide clamps are used to stop the flow by pinching very locally the tubing (fig 1a). Roller clamps are equipped with a small roller which allows the tube to be more or less crushed in order to incrementally occlude it (fig. 1 b). This allows a regulation of the flow rate by defining the size of the tubing lumen. Both kinds of clamps can be found on the same set (fig $1 \mathrm{c}$ ). The aim of this paper was to characterize the effect of both kinds of clamp stresses on the layers found on the internai wall of PVC infusion tubes and the consequences of water injection into the tubing after this stress: we suspected it may lead to a potential higher and faster degradation of the layer with a higher risk of particulate contamination. Indeed, the effect of repeated compression of plastic tubing was studied in the case of hemodialysis circuit ${ }^{6}$; because of the high and complex stress exerted by the peristaltic pump, cracks were observed on the plastic surface and particles were then shed from these defects because of the shear stress exerted on the inner wall of the tubing ${ }^{789} 10$. These particles may then be injected into the bloodstream. This complication is well known in dialysis when using silicone tubing and is called spallation; it was studied by several authors mainly between 1980 and nowadays; it can be implicated in brain dysfunction, granulomatosis hepatitis, macrophage activation... long-term treated patients could show up to $250 \mathrm{mg}$ of silicone particles lodged in organs because of the use of silicone tubing ${ }^{11}{ }^{12}$. But, the PVC used to replace it produces particles too: they were mainly below $5 \mu \mathrm{m}$ in diameter but they can reach $50 \mu \mathrm{m}^{13}$. Moreover, in another publication, Madsen et al. ${ }^{14}$ advised against the stripping of PVC infusion sets with a pair of scissors, by compressing the tubing between the thumb and a scissor blade, a clinical practice used to manage with flow malfunctions: because of this, an increased number of particles $(5$ to $100 \mu \mathrm{m})$ in the infused liquid were detected. 
In a first part, after having discussed the structure and homogeneity of the tube intemal lumen surface, the impact of the different kinds of clamps on the additive layer's morphology will be described and then the impact of water injection on damaged layers will be discussed.

\section{Material and methods}

\section{Material}

Different PVC tubes were used for this study. These tubes were chosen because, as we shown in a previous paper ${ }^{1}$, they had internai layers with very distinct morphologies. For the AFM studies, tubes were cut in $10 \mathrm{~cm}$ long parts. The tubes came from the following kinds of infusion sets: Infusomat ${ }^{\circledR}$ Space line (old reference with DEHP as a plasticizer), Intrafix® SafeSet (BBraun, Germany) and Volumat ${ }^{\circledR}$ Line (Fresenius Kabi, Germany). Intrafix ${ }^{\circledR}$ contains DEHT as a plasticizer and Volumat ${ }^{\circledR}$ line contains TOTM. The dimensions of the tubes are given in table 1 and were very similar; typical plasticizer ratios were between 37 and $40 \%$ (see ref). Typical commercial tubes for infusion are made in relatively soft materials with a shore $A$ index between 65 and 80 . For this study, a same production batch was used for each reference.

\begin{tabular}{|l|l|l|l|}
\hline & Infusomat & Intrafix & Volumat \\
\hline Internai diameter $(\mathrm{mm})$ & 3 & 3 & 3 \\
\hline Extemal diameter $(\mathrm{mm})$ & 4.1 & 4.1 & 4.1 \\
\hline
\end{tabular}

Table 1: dimensions of the tubes used

\section{Mechanical stress}

Stress was applied by using a rolling clamp or by using a pinch clamp. To insure that the analyzed region by AFM corresponds to a stressed one, the pinch clamp and the roller were used on the whole length of the cut tube part. In both case compressive stress was applied on the tube. In the case of the roller clamp, the tube was progressively crushed on a large portion of the tubing to reach a maximum stress when the flow is completely blocked. The roller uniformly compresses the tube sides to confine its cross-section. For the pinch clamp, 
the compression stress was exerted locally by the two jaws and shear stress can occur if their edges are misaligned.

To study the impact of a clamp stress in a case of an infusion act, the tubing was first stressed by the clamps and then an infusion by gravity act was mimicked by infusing $40 \mathrm{mI}$ of filtered water (Direct Q UV ultrapure water type 1). After letting the sample dry, it was analyzed. For this study, only Infusomat ${ }^{\circledR}$ and Intrafix ${ }^{\circledR}$ tubes were analyzed.

a)

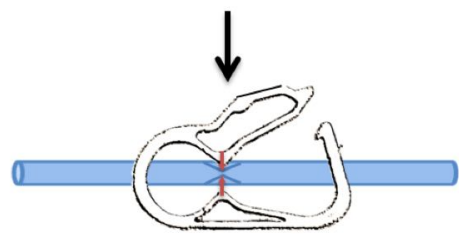

b)

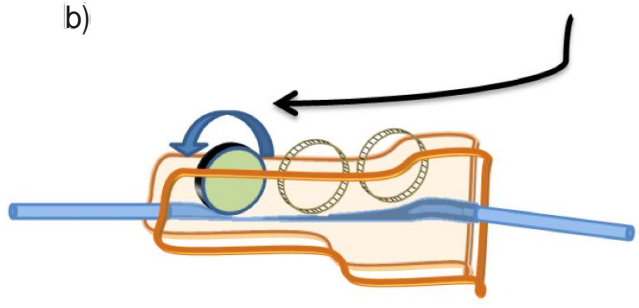

c)

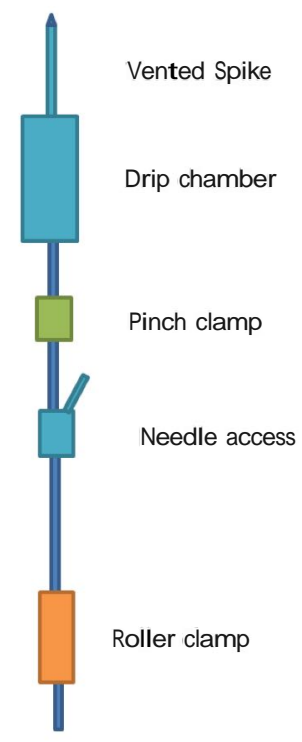

Figure 1: a) pinch clamp that allows stopping the flow by pinching the tube between two jaws b) roller clamp: the drawing shows the movement of the roller along the tube which it crushes progressively to regulate the flow rate $\mathrm{c}$ ) example of placement of clamps on a standard primary set (Volumat@VLST22)

\section{$\underline{\text { AFM }}$}

Tapping mode

The analyses were performed with an Innova AFM (Bruker, Palaiseau, France). The tapping mode in air was used (cantilever frequency $=320 \mathrm{kHz}$, stiffness $=42 \mathrm{~N} / \mathrm{m}, \mathrm{NCHV}$ probe from Bruker). At least six different areas of each sample (a sample corresponds to a $10 \mathrm{~cm}$ long part of a tube) were imaged using a scan rate between 0.5 and $1 \mathrm{~Hz}$. Three samples were used for each tube analyzed: one for studying the non-stressed state, one for 
studying the impact of pinch clamp and another one for studying the impact of roller clamp. For the impact of water injection, three samples of another tube were used (one for the nonstressed state, one for the stressed tube before infusion and the last one for the stressed tube after infusion).

\section{Force imaging mode}

The AFM used was a Nanowizard III (JPK Instruments AG, Berlin, Germany) using Quantitative Imaging ${ }^{\circledR}(\mathrm{QI})$ mode which is a force curve imaging mode. Force distance curve was realized for every pixel of the image. The probes were CSC 37 (Micromasch, stiffness around $0.35 \mathrm{~N} / \mathrm{m}$ ). The stiffness data were calculated from the slope of the force versus scanner elongation curves in the repulsive regime. For every point, the maximum applied force (set-up value) to the sample was $2 \mathrm{nN}$. This analysis was used for studying the impact of water injection on stressed tubes because by using adhesion and stiffness measurements it is possible to easily identify the areas where the additive layer was removed. It was indeed showed in a precedent paper ${ }^{1}$ that polymer surface was softer but has a higher interaction with the tip as compared to the bloomed additive layer.

\section{FTIR-ATR}

The spectrometer apparatus was a Perkin Elmer (Courtaboeuf, France) Spectrum Two used in the ATR (Attenuated Total Reflection) mode with a diamond crystal (500 to $4000 \mathrm{~cm}$ ') and a LiTaO3 (lithium tantalate) MIR detector with a SNR of 9,300:1. 8 scans were performed with a resolution of $4 \mathrm{crn}$ ', The inner surfaces of each sample were analyzed at least on 10 different points of the surface. For FTIR studies, $20 \mathrm{~cm}$ long tube samples were used: for each condition (stressed, not stressed, pre and post infusion), two different tubes were analyzed, and, for each tube, infusion was realized on two different parts of the same tube

\section{$\underline{\mathrm{IR} \text { nanospectroscopy, AFM IR }}$}


134 NanolR2 (Anasys Instruments, CA USA) was used; the AFM microscope is combined with 135 an infrared pulsed tunable laser to perform infrared analysis under the AFM tip. The laser 136 was a multi-chip quantum cascade laser QCL (MIRCAT, Daylight solution, CA USA) ranging 137 from $1530 \mathrm{crn}$ ' to $1850 \mathrm{~cm}$ ", The repetition rate of this source is tunable (1 $\mathrm{kHz}$ to $500 \mathrm{kHz}$ ) 138 and was chosen to match the contact resonant frequency of the AFM cantilever. The beam 139 was focused from the top side of the sample onto the AFM cantilever. A gold coated probe 140 was used (MikroMasch : HQ:CSC38/Al-BS-50 - spring constant 0,03 N/m - resonance 141 around $190 \mathrm{kHz}$ ).

142 The spectra were collected with $1 \mathrm{~cm}$ " spectral resolution.

A FlexSEM 3000 (Hitachi) was used in back scattered electron mode (15 kEV) to image the internai lumen surface of the tube

\section{Results and discussion}

\section{$\underline{\text { Initial texture of the layer }}$}

As already mentioned in a previous paper 1, the morphology of the inner layer was very different depending on the tubing reference. But the topography was quite uniform along the same tubing with very consistent images, especially at the $20 * 20$ or $10 * 10 \mu \mathrm{m}^{2}$ scales. However textures might vary depending on the commercial batch: even if the structures of the different batches have a quite high degree of similarity, discrepancies were observed between batches and even between tubes of the same batch; this may come from small variations in the production process or in the aging of the sample (time between production and analysis, temperature...).That is why, for more convenience and accuracy, we compared the impact of stress and infusion only on several parts of a same tube for AFM studies. 
159 publication ${ }^{1}$, we observe similar but not identical structures. For the Intrafix ${ }^{\circledR}$ sample (fig

160 2.a.b) big ovoid and smooth nodules (20-30 nm high) were still present (mostly-around 3-

$1616 \mu \mathrm{min}$ length and $2 \mu \mathrm{min}$ width), surrounded with thin protrusions (less than 0.2 to $1 \mu \mathrm{m}$

162 wide and between $20-50 \mathrm{~nm}$ high) ; the rms roughness was equal to $9.5 \pm 0.6 \mathrm{~nm}$ for $\mathrm{Rq}$

163 and $7 \pm 0.5 \mathrm{~nm}$ for $\operatorname{Ra}\left(20^{\star} 20 \mu \mathrm{m}^{2}\right)$. For Volumat $\Theta$, a kind of network of protrusions $(5-10$

$164 \quad \mathrm{~nm}$ high and less than $1 \mu \mathrm{m}$ wide) was observed but the layer was less uniform and

165 smooth than the samples previously analyzed from another batch (fig 2.c d): the

166 roughness was $6.3 \pm 1.4 \mathrm{~nm}$ for $\mathrm{Rq}$ and $4.6 \pm 1.1 \mathrm{~nm}$ for $\mathrm{Ra}\left(20 \star 20 \mu \mathrm{m}^{2}\right)$. 


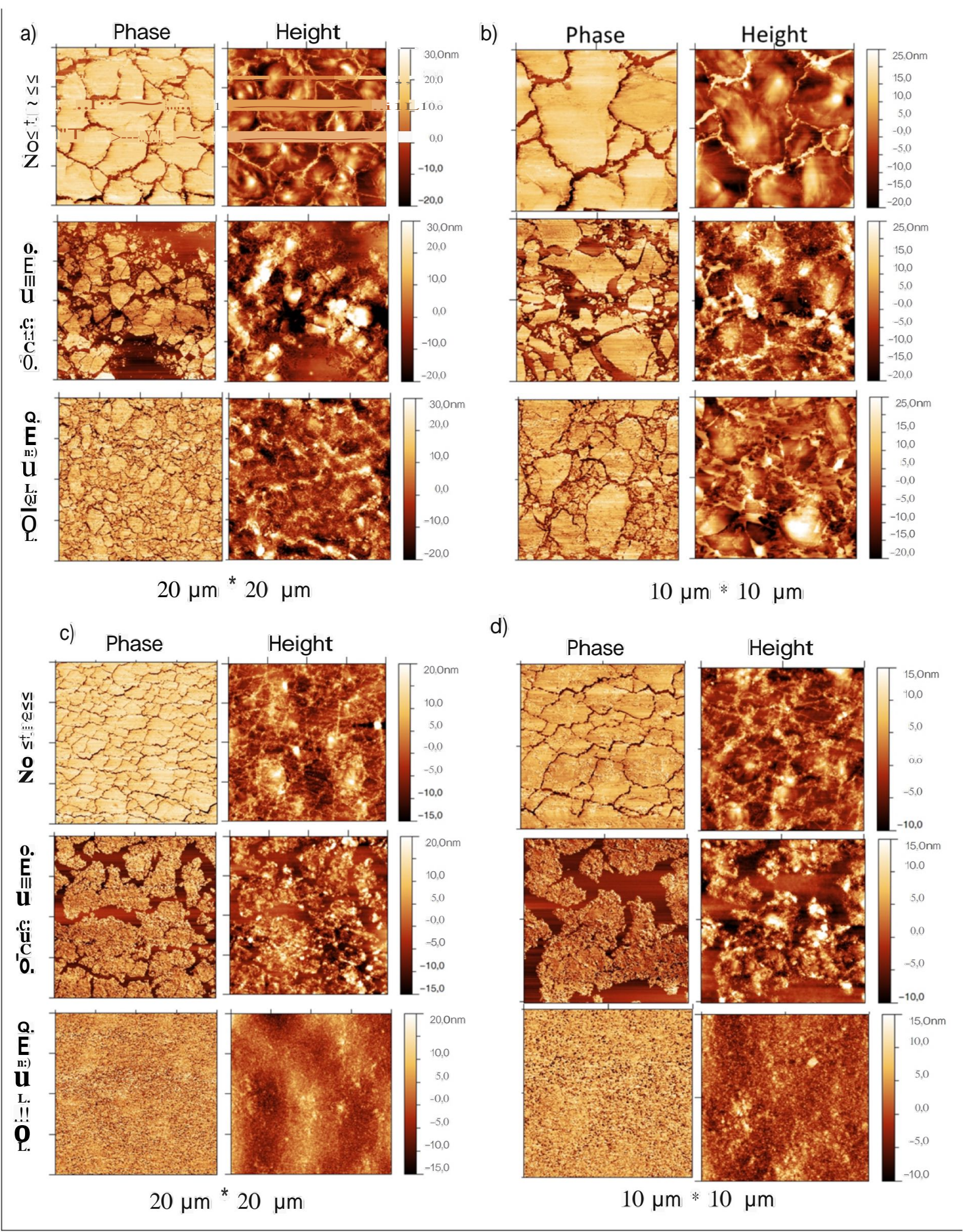

Figure 2: AFM images (height and phase) in tapping mode of the internai layer a) of the Intrafix ${ }^{\circledR}$ tube $20 * 20 \mu \mathrm{m}^{2}$. b) of the Intrafix $\AA$ tube $10^{*} 10 \mu \mathrm{m}^{2}$ c) of the Volumat $\Theta$ tube $20 * 20$ $\mu \mathrm{m}^{2} \mathrm{~d}$ ) of the Volumat ${ }^{\circledR}$ tube $10^{*} 10 \mu \mathrm{m}^{2}$ 

surface was $7.1 \pm 1 \mathrm{~nm}$ for $\mathrm{Rq}$ and $5.3 \pm 0.9 \mathrm{~nm}$ for $\mathrm{Ra}\left(10^{*} 10 \mu \mathrm{m}^{2}\right)$.
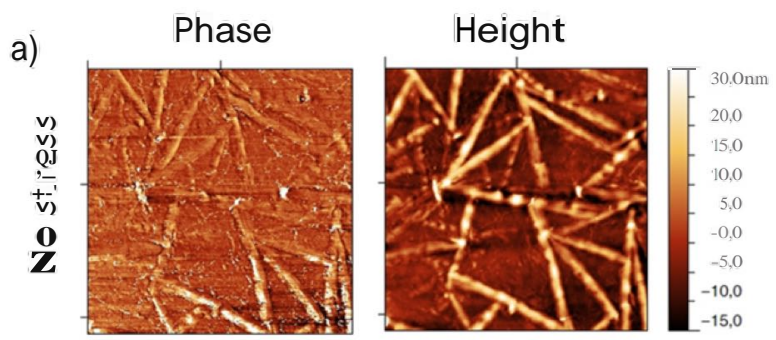

b)

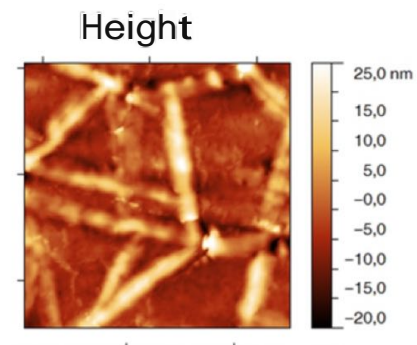

Phase
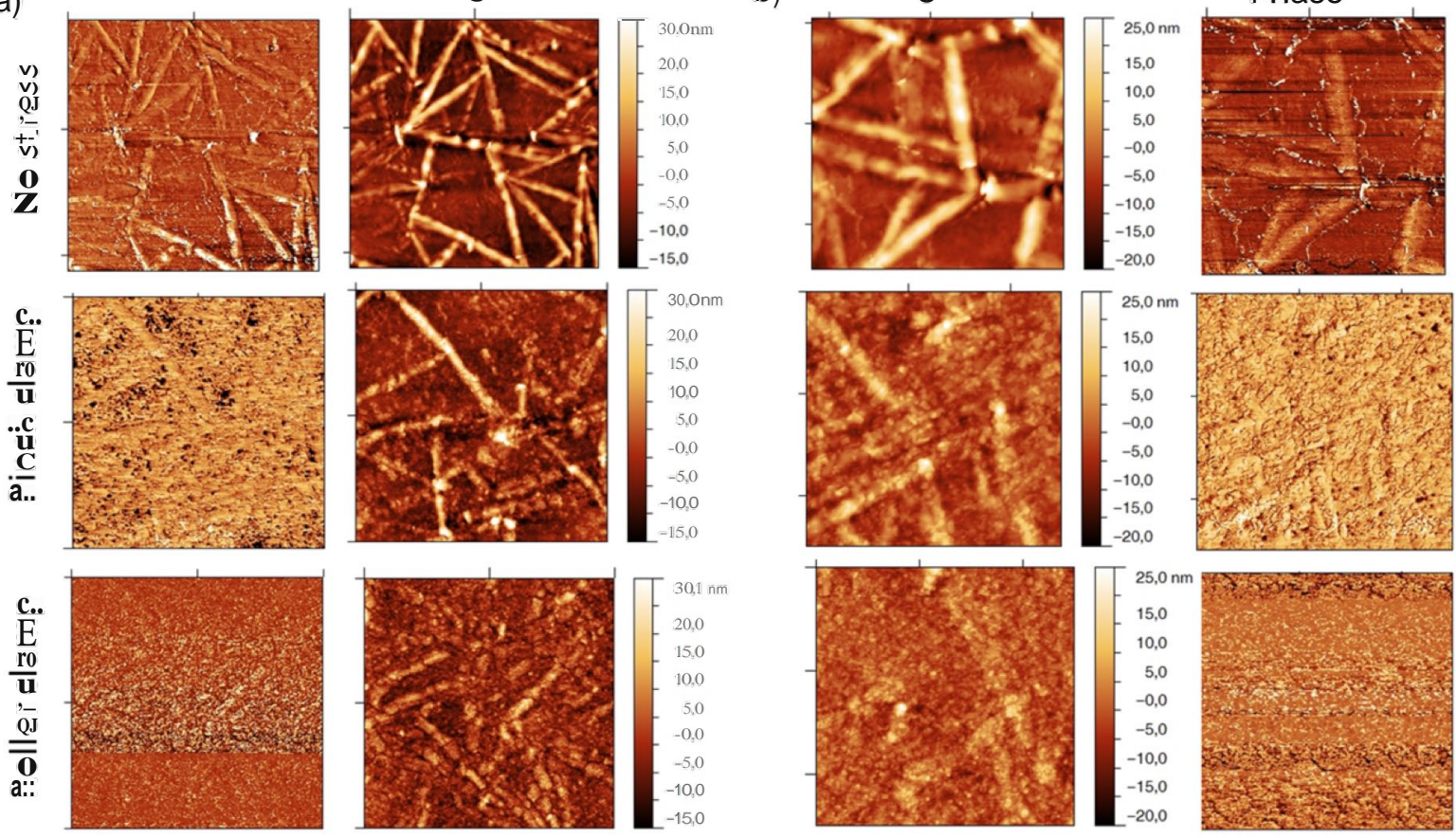

$10 \mu \mathrm{m} * 10 \mu \mathrm{m}$

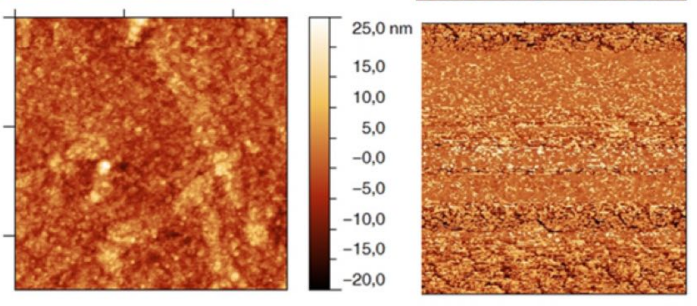

$5 \mu \mathrm{m}{ }^{*} 5 \mu \mathrm{m}$

Figure 3: AFM images in tapping mode (height and phase) of the internai layer of the Infusomat ${ }^{\circledR}$ tube. Scan sizes are either a) $10^{\star} 10 \mu \mathrm{m}^{2}$ or b) $5^{\star} 5 \mu \mathrm{m}^{2}$

It was previously showed that these layers were made of bis-amide lubricant (EBS) and of zinc and calcium stearates ${ }^{1}$, which are additives contained in PVC able to bloom and recrystallize onto the surface. The repartition of the different compounds however is not easy to characterize because of the small thickness of the bloomed layer. Thanks to the Intrafix ${ }^{\circledR}$ tube analysis by nanolR and SEM backscattered electrons (fig. 4), it is however possible to see that the composition of the layer may change very locally, with some area much or less rich in metallic stearates. 
a)

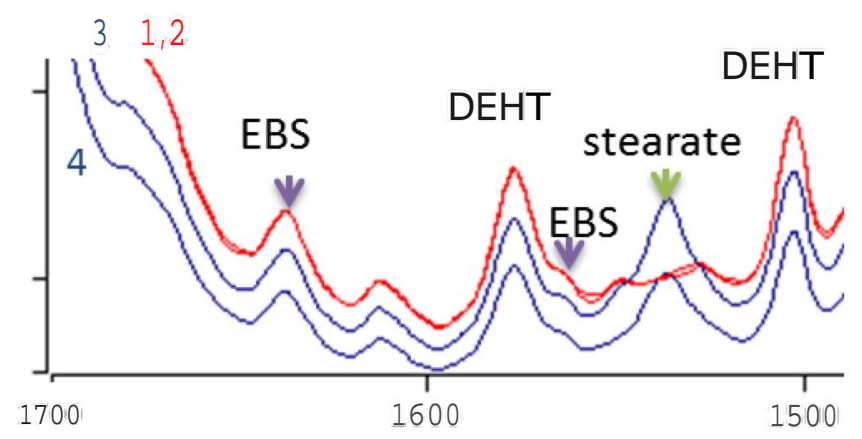

b)

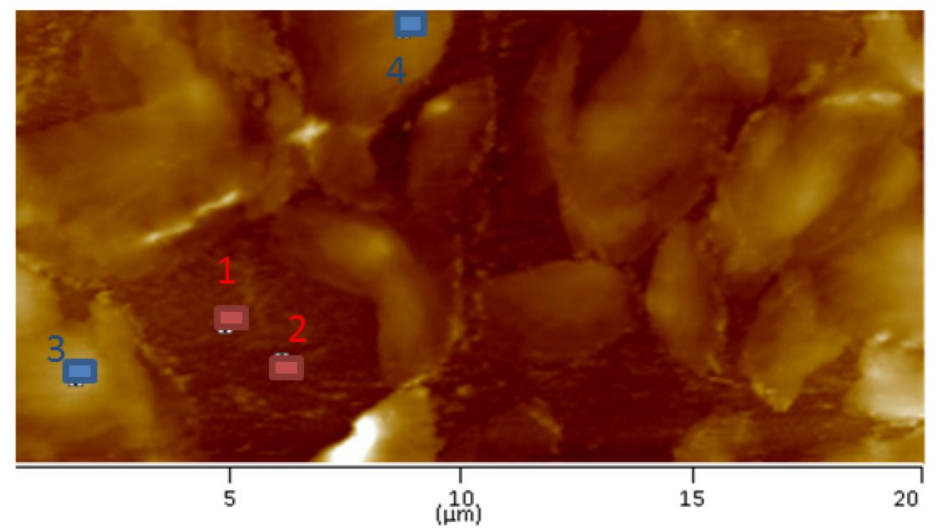

c)

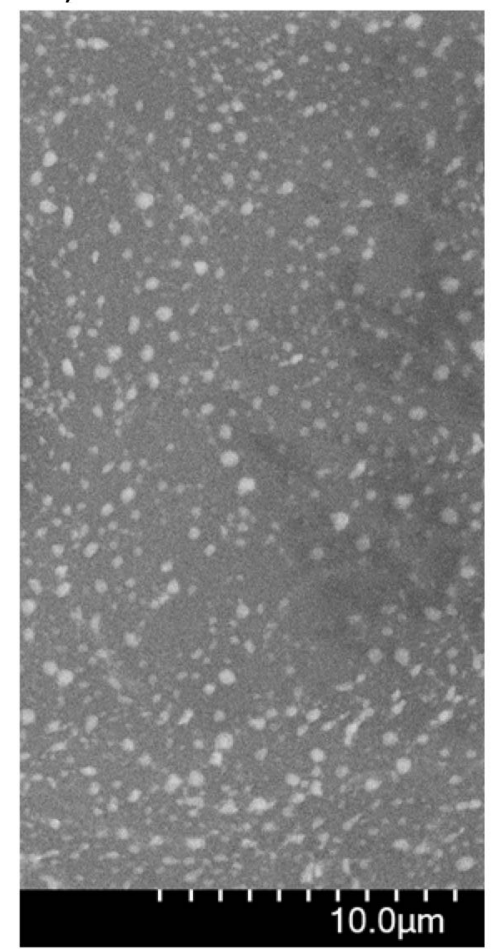

Figure 4: a) Local IR spectra obtained on the surface of Intrafix using IR nanospectroscopy, AFMIR b) AFM height image of the surface with dots corresponding to the spectra c) backscattered electrons SEM image of Intrafix intern lumen. Three contrasted zones appear in the images; the brighter correspond to the higher atomic numbers; the different area may be due to the repartition of $Z n$ stearates $(Z z n=30)$, calcium stearates $(\mathrm{Zca}=20)$ and lubricant (only $\mathrm{C}, \mathrm{O}$ and $\mathrm{N}$ atoms)

\section{Impact of pinch and roller clamps}

The topography (roughness and texture) was impacted by the mechanical stress but it may differ depending on the initial layer topography and on the nature of the clamp used. For example, the pinch clamp has a trend to increase the roughness (fig 5.a.b) and to locally dislocate the layer with significant parts of it that were clearly detached from the PVC surface (this can be seen by analyzing conjointly phase and height images on the fig 2; the area of lower height are not in the same color in the phase image 
suggesting it is only bare PVC surface and no more a bloomed additive layer). This was true for Intrafix $\AA^{\circledR}$ and Volumat $\oplus^{\circledR}$ layers. However, this was not the case for the Infusomat ${ }^{\circledR}$ layer: the kind of needle-like structure seems to be crushed, flattened and it seems that no part of the layer was removed (fig 3). As a consequence, in this case, the roughness was slightly decreased (fig $5 \mathrm{c}$ ). In a general way, the crushing of the tubing by roller clamp has a trend to reduce the roughness by crushing, flattening and smoothing efficiently the layer (fig 2-3). This was very significant for Infusomat ${ }^{\circledR}$ and Volumat ${ }^{\circledR}$ tubing: the layer was much more homogenous and uniform after crushing (fig 2c.d-5) and the roughness decreased from $25 \%-30 \%$ for $\mathrm{Rq}$ (fig 5 b.c). This decrease in roughness was not observed for Intrafix $\circledast$, because, by crushing the surface, the very smooth initial surface of nodules was lost because of their fragmentation by the stress (see phase and height images of the fig.2.a.b).

a)

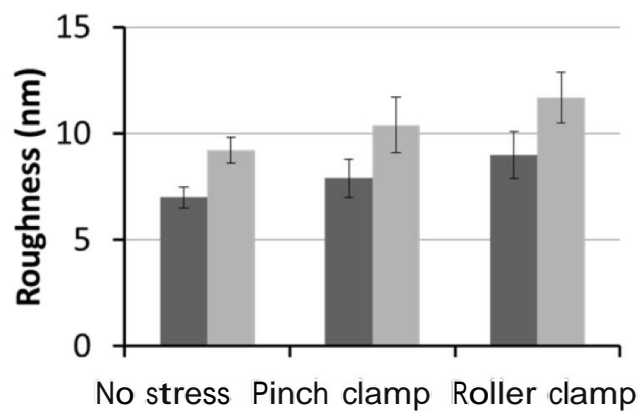

c)

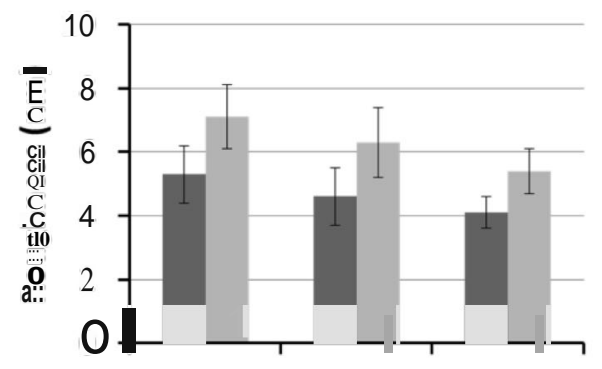

No stress Pinch clamp Roller clamp b)

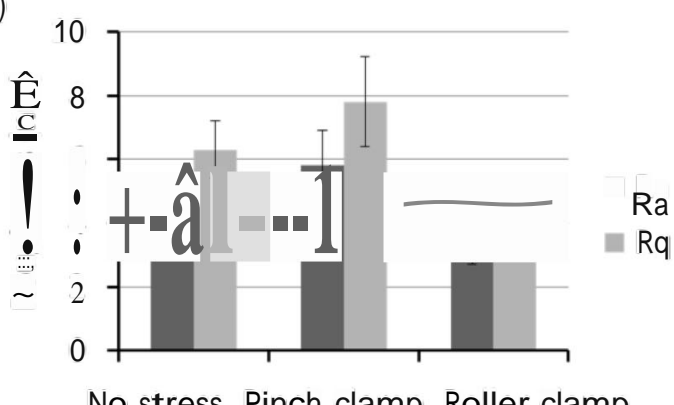

d)

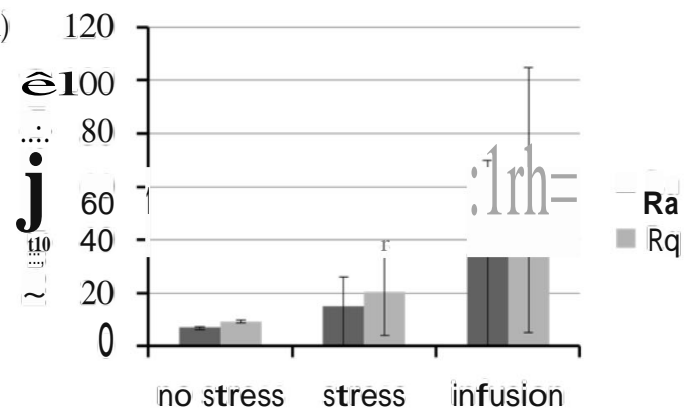

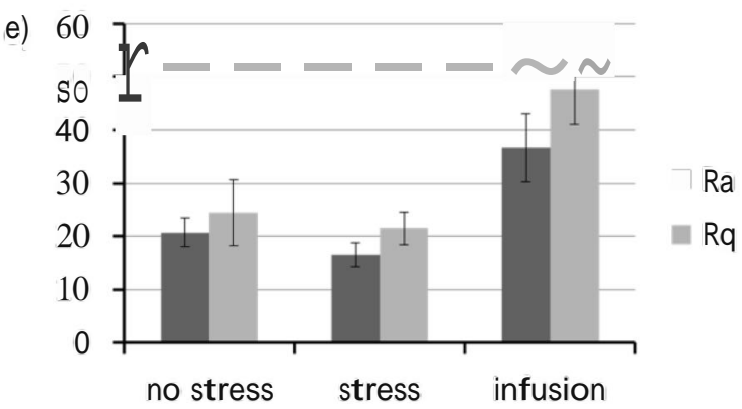


213 Figure 5: Roughness $\mathrm{Ra}$ and $\mathrm{Rq}$ of the inner surface a) for stressed and not stressed Intrafix ${ }^{\circledR}$ $20^{\star} 20 \mu \mathrm{m}^{2}$ b) for stressed and not stressed Volumat $\left(20 * 20 \mu \mathrm{m}^{2} \mathrm{c}\right.$ ) for stressed and not stressed Infusomat $\left(10 * 10 \mu \mathrm{m}^{2} \mathrm{~d}\right.$ ) for stressed Intrafix® before and after infusion $20 * 20 \mu \mathrm{m}^{2}$ Impact of both mechanical stresses followed by water injection into the tubing on the surface morphology

Intrafix®, for which both stresses conduct to a higher roughness and Infusomat@ for which the opposite trend was observed, were subjected successively to both clamp stresses and then water was injected into the tubing. The appliance of the mechanical stresses led to the same trend as before: the stress on the smooth nodules of the Intrafix ${ }^{\circledR}$ layer led to a rougher and more heterogeneous surface (fig $5 \mathrm{~d}$ and $6 b$ ). On the contrary, the Infusomat $(\AA$ layer was flattened and smoothed (fig $5 e$ and 7d). this flattening was very clear on the force images (fig.7), because initially there were some kinds of crazes (fig 7a) in the layer of the studied tube; we observed on fig $7 \mathrm{~b}$ and $7 \mathrm{c}$ that these crazes correspond to areas that were less rigid and have a higher interaction with the tip and thus may be characteristic of bare PVC surface. After mechanical stress, the crazes tend to disappear (fig $7 \mathrm{~d}-\mathrm{f}$ ). 
a)

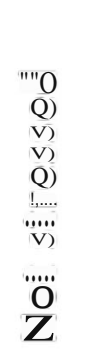

)
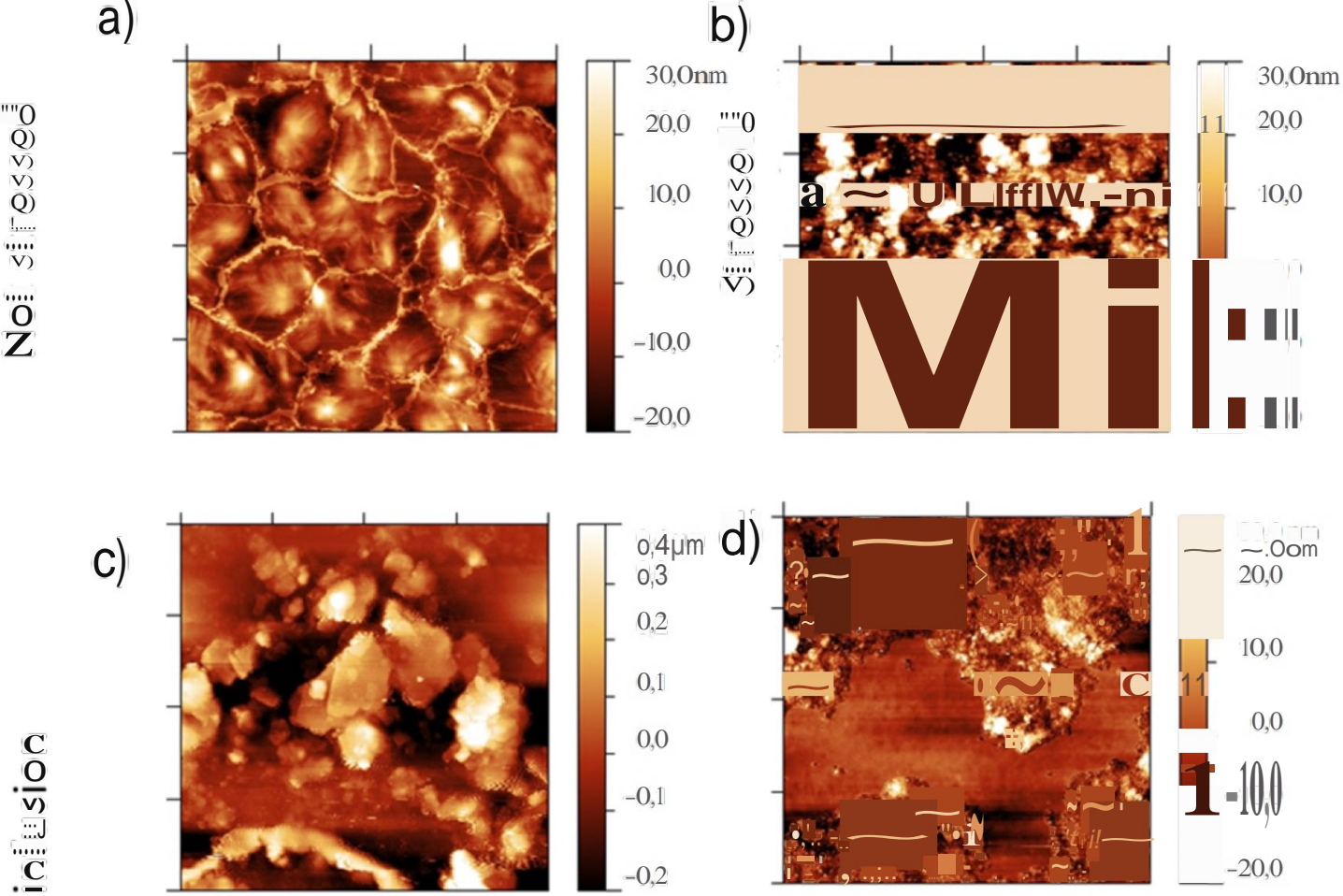

d)
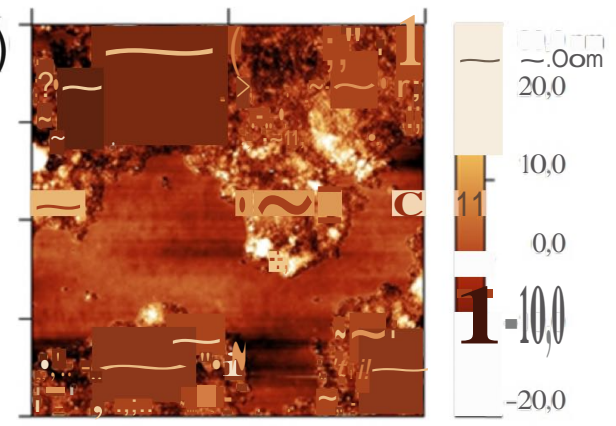

e)

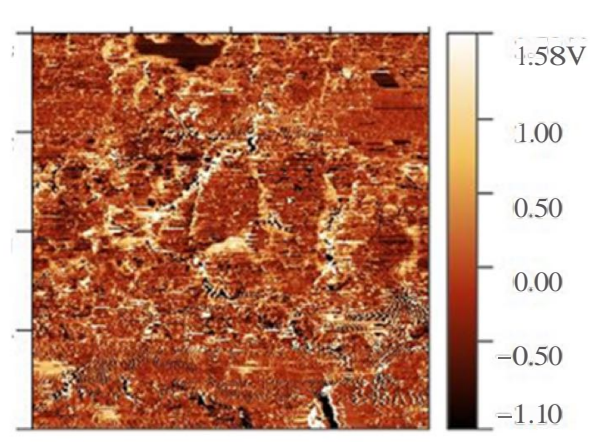

f)

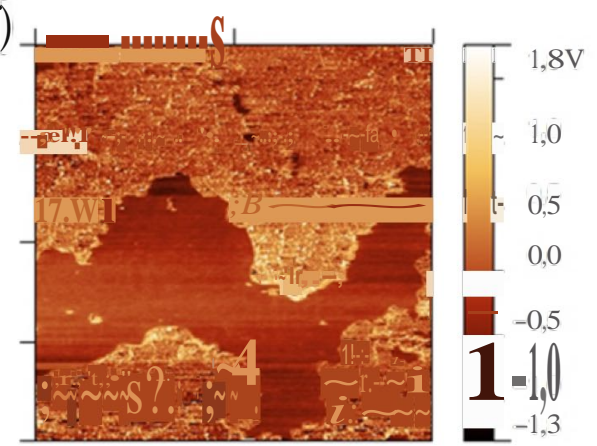

Figure 6: AFM images in tapping mode of the intemal layer of the Intrafix® tube $20 * 20$ $\mu m^{2}$. a) Height image of the initial state b) height image after stress and before infusion c-d) height images of different areas after stress and infusion e-f) Phase image corresponding to the height images after stress and infusion

However, after the water injection, an increase in roughness was clearly observed for the both tubes (fig $5 \mathrm{~d}, \mathrm{e}$ ). Their surfaces become much more chaotic, with the presence of big deposits (fig $6 \mathrm{c}$ and $7 \mathrm{~g}$ ). Surface state may change a lot between two areas and it explained the great dispersity of the roughness in particular for Intrafix ${ }^{\circledR}$ tubing. Moreover in the case of Intrafix $\Theta$, we observed several areas for 
which the additive layer was in part detached after the infusion (fig $6 \mathrm{~d}$-f); this was suggested by the comparison of height image $6 \mathrm{~d}$ to its phase image $6 \mathrm{f}$ : lower height
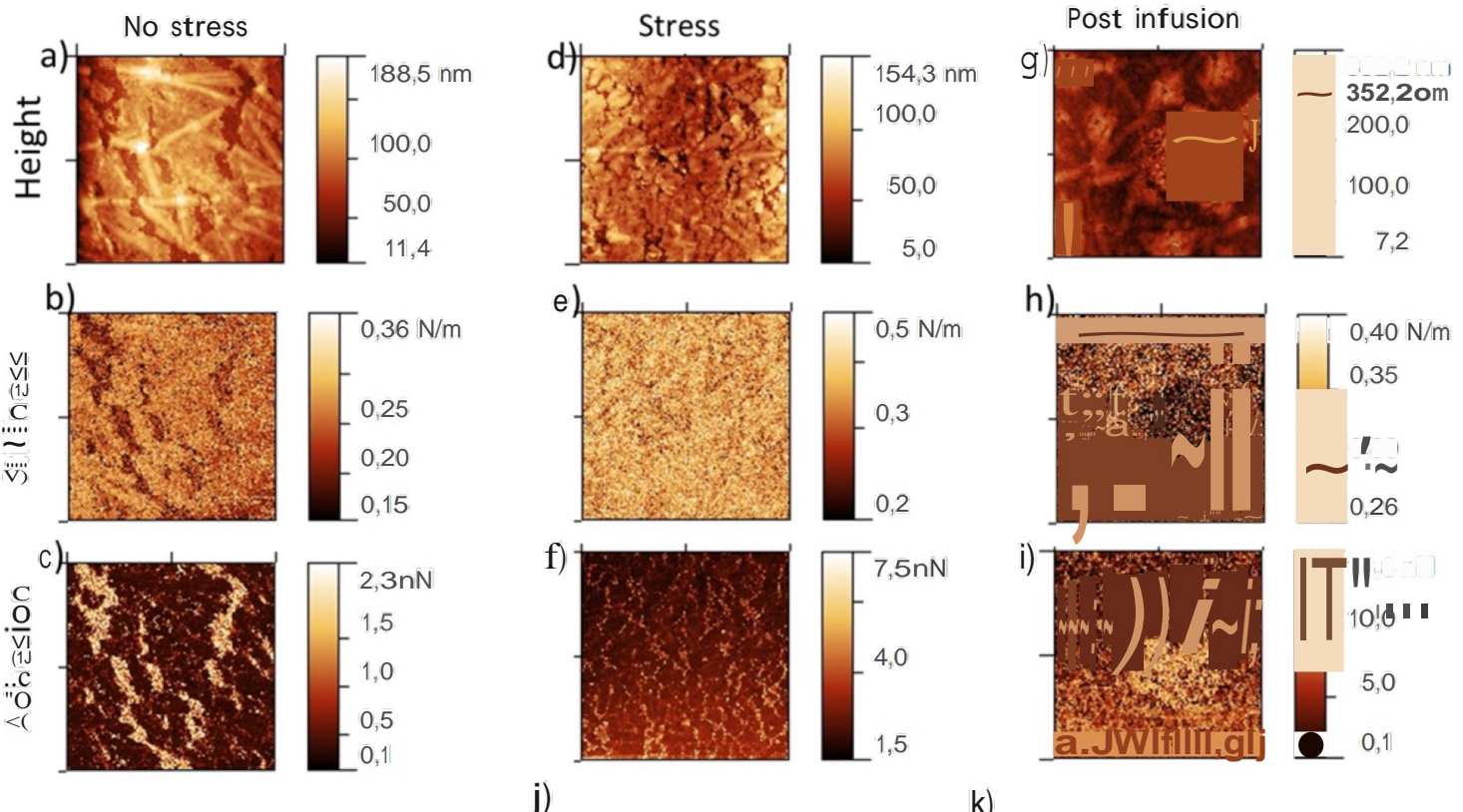

f)
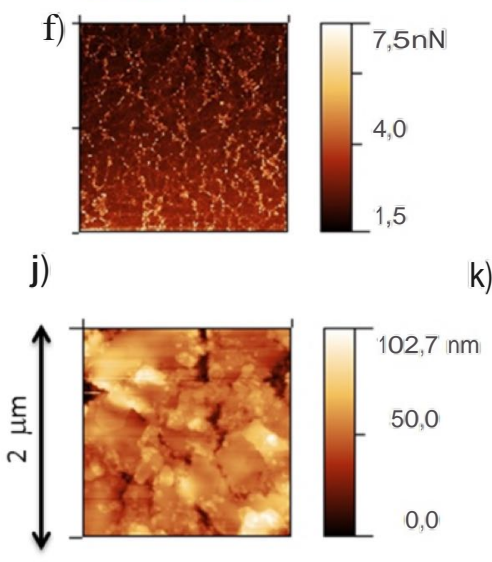

h)
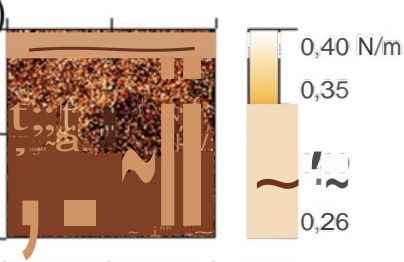

i)
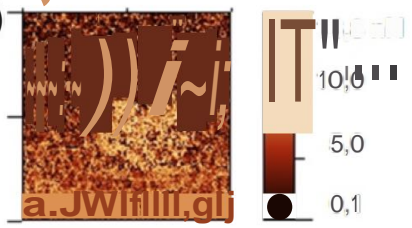

k)
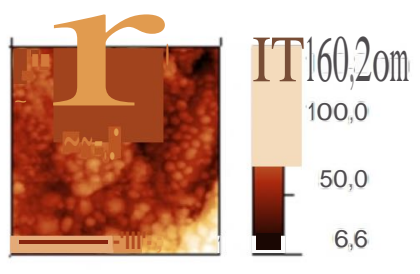
Figure 7: Infusomat ${ }^{\circledR}$ tube a-k) AFM images in force imaging mode of the internai layer of the tubing. a-c) Initial state d-f)j) after both stresses pre infusion $\mathrm{g}-\mathrm{i}) \mathrm{k}$ ) after both stresses post infusion.; $a, d, g, j, k$ are height images ; b, e, h are stiffness images and c,f, $i$ are adhesion images. Scan size is $10^{*} 10 \mu \mathrm{m}^{2}$ except for $\left.\mathrm{j}\right)$ and $\left.\mathrm{k}\right)\left(2 * 2 \mu \mathrm{m}^{2}\right)$

\section{FTIR-ATR analysis}

We focused on the analysis on the $1660-1500 \mathrm{crn}$ ' range because there are characteristic bands of the lubricant $(1637 \mathrm{~cm})$ and of the metallic stearates (Ca: $1535+1574 \mathrm{crn}$ ', Zn: $1535 \mathrm{~cm}$ ) ) in this range. The band positions for stearates are however very dependent on the crystalline state and the formation of complexes 1516 17. As the analysis was performed in ATR mode, it focused on an area close to the surface and was useful to put into evidence the additive blooming. For the tubing batches studied in this paper, the FTIR spectra are given on figure 8 . For Intrafix $\circledast$, we observed a small band for EBS at $1637 \mathrm{crn}$ ' and two bands at 1574 and $1538 \mathrm{crn}$ that can be attributed to metallic stearates. For Infusomat $\AA^{\circledR}$, a band was clearly observed for the lubricant at 1537 crn': moreover some bands were observed at 1568 and $1555 \mathrm{~cm}$ " which can be attributed to EBS or mix of stearates complexes and EBS. The bands were normalized by using a plasticizer band (DEHP band at $1580 \mathrm{crn}$ ' for Infusomat ${ }^{\circledR}$ and DEHT band at 1578 crn' for Intrafix $\left.{ }^{\circledR}\right)$ and we compared the band ratio $A 1537 / A 157 a$ for Intrafix $\AA$ and the band ratio $A 1537 / A 15 a 0$ for Infusomat $\Theta$.

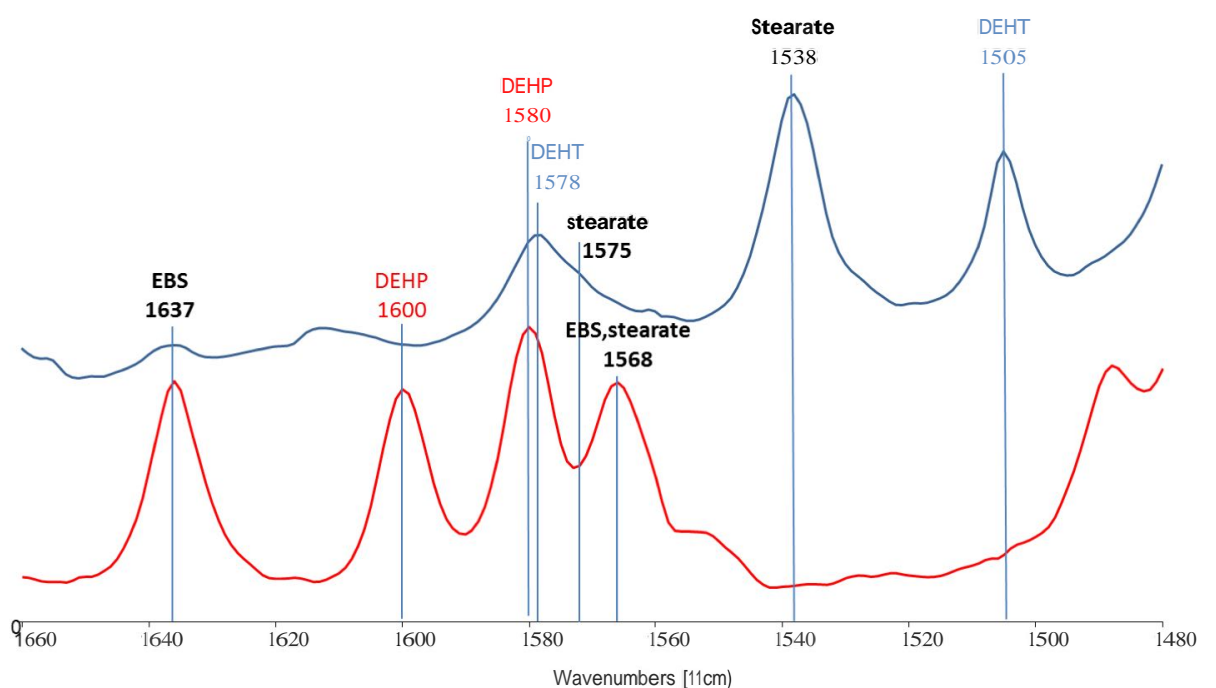


Figure 8: FTIR-A TR spectra of tntreîix" (top blue spectrum) and tnîusomet" (bottom red spectrum) in the $1660-1480 \mathrm{~cm}$ " range.

By working on different parts of a same tube and on different tubes, we observed variations in the precedent band ratios; it should be noticed that the absorbances of the plasticizer band were quite similar on a same sample: for example, the variation coefficient (standard deviation, divided by the absolute value of the arithmetic mean) for the DEHT band absorbance was below $6 \%$ for each sample (before and after stress, before and after infusion); moreover we do not correlate an evolution of this band absorbance with the treatment of the tube (infusion, stress...): the coefficient for all the values of this band absorbance observed on the different parts of a same tube were below $6 \%$ too. The band ratio variations can be mostly correlated to the significant variations of the stearate and EBS band absorbance even before infusion for the not stressed samples: the variation coefficient was between 10 to $64 \%$ for the stearate depending on the sample and between 5 and $117 \%$ for EBS. These variations occur certainly because of thickness variations of the bloomed additive layer along the tube. As a consequence, it was not possible to put into evidence significant variations of the mean absorbance of the bands of the bloomed species after stress, infusion or stress and infusion. In some cases, for the stressed Intrafix@ tube after infusion, some areas without bloomed additive layer were analyzed, but in most cases, the layer was always present on the sample. Moreover the surface analyzed was much bigger than for AFM (crystal size $=2000^{\star} 2000$ microns, that is to say 10000 times higher than our bigger images in AFM): so it is possible that small fragments (only several micrometers wide and several dozen of nanometers thick) detached from the layer that we observed by AFM does not impact in a significant way the band absorbance of the bloomed additives. 
This study proves that the internai layer of infusion tubing made of bloomed lubricant and stearates is quite fragile and can be damaged by the stress exerted by the clamps

Acknowledgement: This work is supported by a public grant overseen by the French National Research Agency (ANR) as part of the "Investissements d'Avenir" program (Labex NanoSaclay, reference: ANR-1 0-LABX-0035). 
3261. 1. Al Salloum, H.; Saunier, J.; Dazzi, A.; Vigneron, J.; Marlière, C.; Aymes Chodur, C.; Herry, J. M.; Bernard, M.; Jubeli, E.; Yagoubi, N. Mater. Sei. Eng. C 2017, 75, 317.

2. Illum, L.; Davis, S. S.; Wilson, C. G.; Thomas, N. W.; Frier, M.; Hardy, J. G. Int J. Pharm. 1982, 12,135.

3. Puntis, J. W.; Wilkins, K. M.; Ball, P. A.; Rushton, D. I.; Booth, 1. W. Arch. Dis. Child. 1992, 67, 1475.

4. Subramanian, P.; Ainsworth, P.; Cassey, J.; Phelan, D. Pediatr. Surg. Int 2002, 18, 658.

5. Garvan, J.; Gunner, B. Med. J. Aust. 1964, $2,1$.

6. Hoenich, N. A. Sernin. Dia/, 1991, 4, 227.

7. Morley, A. R.; Barron, D.; Thompson, P.; Hoenich, N. Á.; Harbottle, S.; Kerr, D. N. S. Med. Eng. Phys. 8, 255.

8. Bednarski Spiwak, A. J.; Horbal, A.; Leatherbury, R.; Hansford, D. J. J. Extra. Corpor. Technol. 2008, 40, 188.

9. $\quad$ Kim, W. G.; Yoon, C. J. Artif Organs 1998, 22, 892.

10. Faria, M.; Liu, Y.; Leonard, E. F. 2017.

11. Leong, A. S.-Y.; Disney, A. P.; Gove, D. W. N. Engl. J. Med. 1982, 306, 135.

12. Laohapand, T.; Osman, E.; Morley, A.; Ward, M.; Kerr, D. 1982; Vol. 19, pp 143.

13. Liu, Y.; Faria, M.; Leonard, E. Artif Organs 2017, 41,672.

14. Madsen, H.; Winding, O. Biomaterials 1996, 17, 663.

15. Ishioka, T.; Maeda, K.; Watanabe, I.; Kawauchi, S.; Harada, M. Spectrochim. Acta. A. Mol. Biomol. Spectrosc. 2000, 56, 1731.

16. Toda, S.; Sakai, A.; Kojima, Y. Spectrochim. Acta Part Mol. Spectrosc. 1971, 27, 581.

17. Mackenzie, M. W.; Willis, H. A.; Owen, R. C.; Michel, A. Eur. Polym. J. 1983, 19, 511.

18. Hadaway, L. C. In Infusion Nursing: An Evidence-based Approach; Elsevier Health Science; Mary Alexander, Ann Corrigan, Infusion Nurses Society, Judy Hankins, 2009; pp 391. 